\title{
HISTORIA
}

\section{HISTORIA DE LA PRENSA PROFESIONAL DE LOS MINISTRANTES Y PRACTICANTES EN ESPAÑ A \\ EN EL SIGLO XIX}

Raúl Expósito González

DUE. Hospital General de Ciudad Real

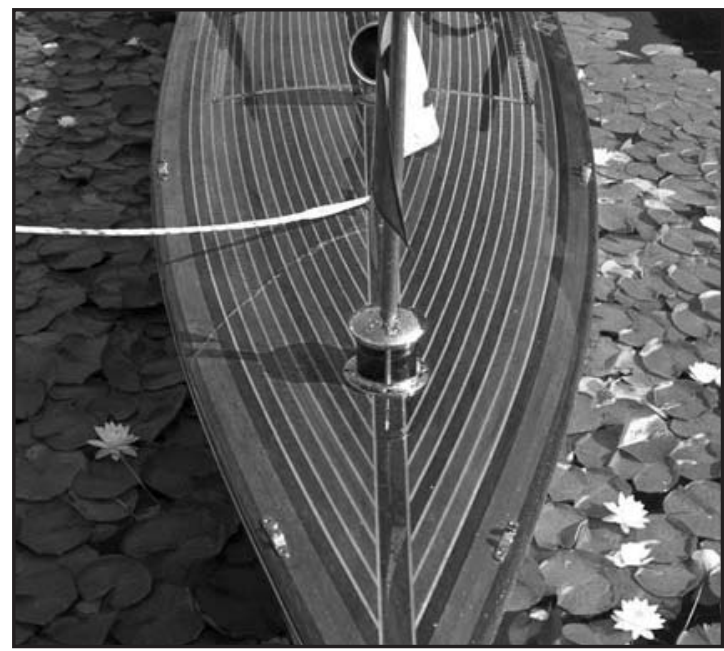

THE PROFESSIONAL PRESS HISTORY OF "MINISTRANTES" AND "PRACTICANTES" IN NINETEENTH CENTURY IN SPAIN

\section{ABSTRACT}

$\mathrm{T}$ The newspapers from the ministrantes and practicantes in Spain supposes a great source of information to recover the past of these health auxiliary profession.

Another researchers have faced this problem focusing on concrete aspects which mainly obbey to the local and/or regional press of the XX century, so in this article we will talk in general about the Spanish press of the nineteenth century of the ministrantes and practicantes. This subject deserved to be treated in more detail.

Key-words: Ministrantes, Practicantes, Health Press.
HISTÓRIA DA IMPRENSA PROFISSIONAL DOS MINISTRANTES E PRATICANTES NA ESPANHA NO SÉCULO XIX

\section{RESUMO}

imprensa dos ministrantes e praticantes na 1 Espanha supõe uma grande fonte de infor1 mação para recuperar o passado destas profissões auxiliares de saúde. Outros investigadores têm estudado esta temática, mas se centram em aspectos específicos que obedecem mais ao estudo da imprensa de âmbito local e/ou regional do século XX. O presente artigo, entretanto, discorrerá, de uma maneira mais geral, sobre a imprensa espanhola do século XIX, e a sua relação com os ministrantes e os praticantes, embora este seja uma temática que mereça ser tratada com mais aprofundamento ou cuidado.

Palabras-chave: Ministrantes, practicantes, Imprensa sanitária.

\section{RESUMEN}

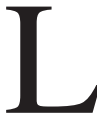

a prensa de los ministrantes y practicantes en España supone una gran fuente de información para recuperar el pasado de estas profesiones auxiliares sanitarias.

Otros investigadores han abordado este tema pero centrándose en aspectos concretos que obedecen más al estudio de la prensa de ámbito local y/o regional del siglo $\mathrm{XX}$ por lo que con este artículo hablaremos de forma general sobre la prensa española decimonónica de los ministrantes y los practicantes, aunque este es un tema que merece ser tratado con más detenimiento. 
Palabras Clave: Ministrantes, Practicantes, Prensa sanitaria.

\section{MINISTRANTES Y PRACTICANTES EN LA PRENSA MÉDICA DEL SIGLO XIX}

Aunque en este trabajo nos centraremos en la prensa del siglo XIX de los ministrantes y practicantes, no hemos de olvidar que las páginas de los boletines de las distintas ramas sanitarias también se hacían eco de los asuntos referentes a la clase cuando estos no contaban todavía con sus propios órganos de expresión.

Los periódicos y revistas de Medicina y Cirugía del siglo XIX -algunos de los cuales añadían a sus denominaciones el apellido o coletilla "y de Ciencias Auxiliares"- también insertaban anuncios y noticias relevantes para las llamadas clases auxiliares médico-quirúrgicas como el mítico periódico madrileño El Siglo Médico, pero no sería el único pues en 1854 en El Albéitar de Barcelona se proponían los ministrantes de esta ciudad dar una hoja suelta en cada número para hacer la defensa de una abandonada clase. Otros periódicos con los que contaron los ministrantes y practicantes para tales fines fueron La Abeja Médica de Barcelona y La Correspondencia Médica de Madrid. Este último estaba dedicado a los médicos, cirujanos, farmacéuticos, ministrantes y veterinarios de España.

Desde 1846 año en que se crea la Cirugía Menor o Ministrante hasta 1857 en que se suprime esta enseñanza para dar paso a la de Practicante transcurren una serie de años y es bien entrada la segunda mitad del siglo XIX cuando aparecen en España los primeros rotativos por y para los practicantes y los ministrantes a extinguir.

\section{RELACIÓN DE PERIÓDICOS}

Para la elaboración de este estudio hemos realizado un índice con diversos periódicos, algunos de los cuales se han conservado hasta nuestros días y son de acceso público en bibliotecas. De otros tantos sabemos que existieron a partir de referencias extraídas de los distintos compendios bibliográficos y de otras obras.

Los periódicos aparecen citados por orden cronológico siendo en algunos casos exacto mientras que en otros es más o menos aproximado teniendo en cuenta las fuentes utilizadas.

\section{La Voz de los Ministrantes (1864) [1]}

Primer periódico dedicado exclusivamente a la instrucción y defensa de la clase de ministrantes y practicantes tal y como rezaba en el encabezado y que vio la luz por vez primera en Madrid el viernes 15 de enero de 1864 haciendo su última aparición en la prensa el 30 de junio de 1867 .

Se publicaron un total de 114 números: inicialmente dos periódicos al mes los días 15 y último y; partir del año 1865 tres números que aparecían los días 10, 20 y último de mes. Constaba cada número de ocho páginas con el texto a dos columnas y se dividía en tres secciones: Profesional, Científica y Varia.

Periódico hecho por y para la clase, su Director fue don Salvador Villanueva, ministrante que ejercía el Arte del Dentista en su gabinete de la Calle Gorguera de Madrid realizando todas las operaciones inherentes a su profesión incluida la llamada prothesis dentaria, y que dedicaba una hora a "operar" gratuitamente a los pobres salvo días festivos. Demostró ser hombre de una cierta cultura no sólo por sus brillantes artículos insertos en estos boletines sino porque en 1866 fue coautor del libro Guía del Cirujano Menor con un apéndice sobre el Arte del Dentista junto a un gran defensor de la clase y socio de mérito del Colegio de Ministrantes y Practicantes de Sevilla, el Doctor en Medicina y Cirugía don José López de la Vega.

Como Administrador del boletín figuraba Jorge Mariscal; como Secretario de Redacción Gerónimo Balaguer; como redactores en el primer número de este periódico Policarpo Martínez (Zaragoza), Manuel Collado (Aranda de Duero, Burgos), Félix Hernán y Francisco Campos; y como Editor responsable Joaquín Girona.

Admitía como colaboradores a todos los ministrantes y practicantes y ya desde su segundo número contaba además de con los corresponsales de Zaragoza y de Aranda de Duero, con los de Barcelona, Teruel, San Felipe de Játiva y Villareal (Castellón).

Existían puntos de suscripción en Madrid, en el domicilio del Administrador en la Calle Atocha, en provincias Zaragoza y Aranda de Duero y en las 
demás capitales de partidos judiciales. La suscripción costaba 8 reales por trimestre en toda España.

De un valor incalculable es esta serie de periódicos del siglo XIX que se ha conservado casi en su totalidad y en la que nos detendremos por ser el Decano de la prensa profesional de los ministrantes y practicantes españoles.

A través de sus páginas, $\mathrm{La} \mathrm{Voz}$ de los Ministrantes nos acerca a la realidad que vivieron aquellos protagonistas que ya desde la cuna veían incierto su futuro sobre todo con el arreglo de los partidos médicos siendo olvidados por completo en la Ley de Sanidad de 1855.

Este periódico apareció en una época muy crítica por los problemas que los practicantes y sus predecesores los ministrantes venían arrastrando desde hacía años. A grandes rasgos, recordemos que en 1843 se unificaron los estudios de Medicina y Cirugía. Esta coyuntura junto al Plan General de Estudios de 1845 fueron aprovechados posteriormente y durante años por las distintas clases de Cirujanos que pretendían acceder a una titulación superior, la de Médico-Cirujano, es decir, buscaban una nivelación. Por medio del citado plan de estudios nació la figura del Cirujano menor o Ministrante, rama subalterna de la Cirugía e injustamente tratada por la clase médica que argumentaba que con su creación se complicaría aún más el entramado de las profesiones sanitarias existente en aquellos días y cuyas atribuciones y competencias pronto entrarían en conflicto con las de los Cirujanos de Tercera Clase. Duramente criticados y repudiados fueron los ministrantes, y sus sucesores los practicantes no corrieron mejor suerte. Fueron herederos de estos males hasta el punto que en 1862 llevó a los Cirujanos de Tercera Clase a apelar a las Cortes exponiendo los prejuicios que les causaba la creación de los practicantes.

Ante esta guerra con los cirujanos que les hacía sentirse como intrusos a pesar de que el título de practicante lo era con carácter oficial, colocó a los practicantes cansados de esta situación en el extremo de pedir su desaparición para integrar una nueva clase de cirujanos que les dotaría de mayores conocimientos científicos según podemos extraer de La Voz de los Ministrantes haciendo suya esta propaganda desde que comenzara a publicarse, dedicando ríos de tinta a un asunto tan serio y de vital trascendencia para el porvenir de la clase. La propuesta fue presentada al Congreso en 1866 por los señores diputados Martín de Herrera y Ortiz de Zárate que encontraron una fuerte oposición en el escaño de Méndez Álvaro y en las filas de El Siglo Médico.

Don Manuel Orovio, Ministro de Fomento promulgaba el 7 de noviembre de aquel año, un Real Decreto por el cual se creaba la figura del Facultativo de Segunda Clase y suprimía la enseñanza de practicante circunstancia que favoreció el optimismo del colectivo pues esta disposición anunciaba que por medio de un reglamento se determinarían los estudios y exámenes necesarios para que las distintas clases de cirujanos cambiasen su título por el recién creado, creyendo que sería extensible a ministrantes y practicantes. El 20 de febrero de 1867, nuevamente Orovio, da luz verde al citado reglamento que permitiría a los ministrantes y practicantes aspirar al título de Facultativo de Segunda Clase, acontecimiento que tuvo gran acogida por significar todo un logro, a pesar de que poco tiempo después sería restablecida la carrera de practicante.

Éste es, a groso modo, el contexto histórico en el que se enmarca la breve pero incesante vida que tuvo La Voz de los Ministrantes alcanzando en 1867 con este reglamento la cota más alta a la que podían aspirar los ministrantes y los practicantes españoles.

Otro de los aspectos que resaltan de este periódico es su espíritu corporativista en los albores del asociacionismo no ya sólo de los ministrantes y practicantes sino también del resto de clases sanitarias. En Madrid parece ser que existía una Sociedad de Socorros Mutuos de Ministrantes aunque en sus Estatutos no aparece, en su denominación, lo de "Socorros Mutuos" - cuyo Reglamento manuscrito tiene fecha de 17 de diciembre de 1862 y está rubricado entre otros por el señor Salvador Villanueva, a la sazón Director de La Voz de los Ministrantes que en agoto de 1864 también figuraba como Presidente de la Junta Directiva de esta Sociedad General de Ministrantes que celebraba sus reuniones en los Salones de Capellanes en Madrid.

Dos años más tarde, en 1864 y tomando el ejemplo de los compañeros de Madrid, en Sevilla 
se estableció un Colegio de Ministrantes y Practicantes siendo su Presidente don Antonio Díaz y su Secretario don José María Baca. Los Estatutos de este Colegio de Sangradores y Practicantes de Sevilla datan del 17 de julio de 1864 y fueron aprobados el 27 de septiembre de 1864 pasando a ser La Voz de los Ministrantes su órgano oficial a partir del boletín número 29 correspondiente al 20 de febrero de 1865 y hasta finales de ese mismo año. Pero no solamente era noticia en Sevilla la creación de un Colegio de Practicantes, pues un año después en 1865 aparecería en la misma ciudad un Colegio de Dentistas cuyo Reglamento orgánico de 1 de diciembre de 1864 fue autorizado por el Gobernador de la provincia de Sevilla el 2 de enero de 1865. Este hecho nos llama la atención por la distinción que existía entre un Colegio para Sangradores y Practicantes y otro para Dentistas que se establecen en la misma ciudad y en tan breve espacio de tiempo, sobre todo teniendo en cuenta que para la realización de tareas como la limpieza de la dentadura y la extracción de piezas dentarias fueron autorizados los cirujanos menores o ministrantes y los practicantes no existiendo aún el título de Cirujano-dentista, pudiendo tratarse estos dos colegios de una misma sociedad.

La Voz de los Ministrantes mantuvo una estrecha relación con el oficio dental. Su Director, Salvador Villanueva era socio del Colegio de Dentistas de Sevilla y en las páginas de su periódico se llegaron a publicar numerosos artículos científicos sobre temas odontológicos. Como mayor muestra de este vínculo es que también acabaría convirtiéndose en el órgano oficial del Colegio de Dentistas de la Provincia de Sevilla a partir del número 63 del mes de enero de 1866 hasta la desaparición del periódico en junio de 1867 que lo haría por la falta de fondos.

\section{El Genuino (1865)}

Como acabamos de ver en 1864 se estableció en Sevilla un Colegio de Sangradores y Practicantes con el objetivo principal de defender los intereses de la clase que acababa de sufrir un serio revés al ser ocupadas -con beneplácito incluido de la administración- por intrusos las cuatro plazas de practicantes de las dos Casas de
Socorro que se acababan de instalar en la ciudad hispalense.

Al igual que ya hiciera su homónimo en Madrid, este colegio empezó a publicar en mayo de 1865 el Boletín del Colegio de Sangradores y Practicantes de Sevilla, bajo el nombre de El Genuino y con la dirección del Presidente del colegio don Antonio Díaz que abandonaba su cargo de corresponsal en $\mathrm{La} \mathrm{Voz} \mathrm{de} \mathrm{los} \mathrm{Ministrantes.}$

Aparecía dos veces al mes, los días 1 y 15 y cada número constaba de ocho páginas y texto a dos columnas.

De este periódico que en febrero de 1867 suspendía su publicación no se han encontrado ejemplares y parece ser que terminó al extinguirse el Colegio de Sangradores del que era órgano (Chaves, 1995).

\section{El Cirujano Menor (1872)}

Periódico madrileño de ministrantes y practicantes cuya publicación comenzó en noviembre de 1872 (Méndez, 1978) aunque otros autores señalan que se publicaba desde 1860 (Martínez, 1911). Su Director fue don Joaquín Estevez. Cada número constaba de ocho páginas con texto a dos columnas y se publicaba tres veces al mes. Al finalizar el año 1872 desapareció y en enero de 1873 le sucedió El Cirujano siendo su Administrador don Gerónimo Balaguer, el otrora Secretario de Redacción de La Voz de los Ministrantes. No obstante, este boletín también tuvo una vida muy corta.

\section{La Cirugía Menor (¿1883-1904?)}

Sobre la existencia de esta revista barcelonesa hay datos que nos indican que su aparición tuvo lugar entre 1883 y 1900 (Calbet, 1967). Sin embargo, hay quienes señalan que hizo su incursión en el mundo de la prensa sanitaria en pleno siglo $\mathrm{XX}$, concretamente en 1903 (De Larra, 1905) pero también en 1904 (Martínez, 1911).

Desconocemos si don Manuel Montaner y Gimeno fue su primer Director ya que así figuraba como tal en 1903. El Secretario de Redacción en 1904 era don José Cirach y Mulet, anteriormente redactor de La Lanceta y al igual que muchos practicantes de la época que se dedicaban a la odontología aprobó los exámenes de reválida de Cirujano-dentista en 1893. 


\section{La Lanceta (1883) [2]}

A la hora de hablar de los pioneros en el asociacionismo de ministrantes y practicantes los investigadores siempre han tomado dos referencias, la Sociedad General de Ministrantes de Madrid y el Colegio de Sangradores y Practicantes de Sevilla surgidos en los primeros años de 1860. Sin embargo, no debemos olvidar que Cataluña también lo fue, ya que en la Ciudad Condal funcionaba una sociedad bajo la denominación de La Unión de Cirujanos, Ministrantes y Practicantes de Barcelona. No podemos cifrar el origen exacto de su fundación que tuvo que ser muy próxima al mes de mayo de 1866, fecha de la que datan sus Estatutos. Otros autores creen que pudo aparecer a partir de 1859 e incluso ser anterior a las mencionadas sociedades o colegios de Madrid y Sevilla.

Esta Unión, tenía por objeto perseguir en todos los terrenos la intrusión en la profesión de cirugía y defender los derechos profesionales de la misma, pudiendo formar parte de ella todos los Cirujanos, Ministrantes y Practicantes residentes en Barcelona.

Pasaron una serie de años desde la constitución de esta sociedad hasta que se concedió autorización a favor de don Pedro Caralt para que empezara a publicarse el periódico La Lanceta órgano oficial de La Unión de Cirujanos, ministrantes y practicantes de Barcelona, saliendo a la luz el primer número el día 15 de noviembre de 1883. El Propietario don Pedro Manaut y Taberner comenzó siendo el Director Científico del periódico sustituyéndole después don Jaime Vilar y Colom. El Redactor-jefe en 1887 era el practicante don Pedro Maza y Fiestas secundado por el también practicante don Juan Lloveras y Marimón y otros redactores.

Este periódico en un principio saldría una vez al mes pero partir de agosto de 1884 pasaría a ser quincenal publicándose los días 15 y 30 , siguiendo el mismo formato que los periódicos de aquella época con ocho páginas y texto a dos columnas.

La cuestión de la asociación y colegiación siempre estuvo presente en la mente de la clase que luchaba por su reconocimiento profesional, apareciendo así las primeras asociaciones de practicantes en varias ciudades españolas como Madrid, Sevilla, Barcelona y Zaragoza. Precisamente el 2 diciembre de 1884 se constituye la Junta

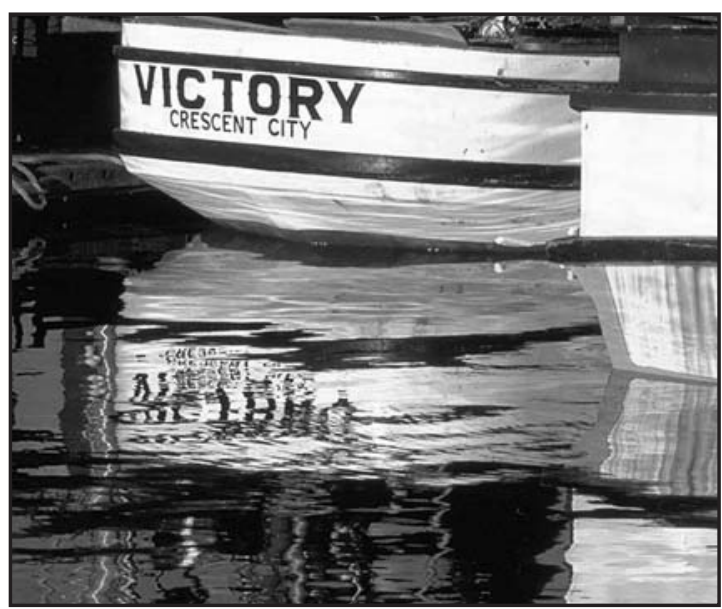

Provincial de Practicantes en la invicta ciudad de Zaragoza tras ser elegidos los miembros integrantes de la Comisión Gestora de la Asociación General de Practicantes de España, llegándose a editar una circular con el Reglamento de dicha Asociación que es enviada a todos los practicantes españoles teniendo gran acogida formándose las primeras Juntas de practicantes en distintas provincias y partidos.

La Comisión Gestora de esta Asociación presidida por don Apolonio Elorz tenía como fin estimular la creación de Asociaciones de Practicantes en todas las provincias del país que funcionarían de forma autónoma pero en armonía con la central. La labor impulsora y de organización de la Comisión Gestora concluiría cuando se convocase un Congreso en el que se nombraría la Junta Suprema de la Asociación y se designaría su punto de residencia (Herrera, 1995a).

En la vecina Barcelona se hicieron eco de la idea de sus hermanos zaragozanos y La Lanceta convocaría a todos los practicantes de la provincia a una reunión el día 12 de enero de 1885 para tratar el asunto de la asociación de todos los practicantes de España y de la que saldría elegida la Junta provincial de practicantes de Barcelona.

Un acontecimiento importante para los ministrantes y practicantes fue la celebración en Barcelona - a propuesta del doctor don Pedro Manaut y Taberner, Presidente honorario de La Unión de Cirujanos, ministrantes y practicantes de Barcelona - del ansiado Congreso Español de Cirujanos, Ministrantes, Practicantes y Cirujanos- 
dentistas que en un principio iba a tener lugar los días 24, 25, 26 y 27 de septiembre de 1884 y que a consecuencia de la epidemia de cólera que azotó a toda Europa fue aplazado celebrándose finalmente los días 7, 8 y 9 de abril de 1885. Actuaron como Secretarios de la Mesa los practicantes don Pedro Maza y don Sebastián Bonastre, redactores de La Lanceta. A dicho Congreso concurrieron 140 asistentes y se tomaron, entre otros, los acuerdos de pedir al Gobierno la refundición de las tres carreras de practicantes de la Armada, cirujanos, dentistas y ministrantes, ampliando los estudios para constituir una profesión análoga a la de los antiguos cirujanos, así como que obligase a los Ayuntamientos a crear plazas titulares de cirujanos. También se acordó nombrar un Comité Central de la clase de practicantes, que residiría en Madrid, y una Comisión encargada de indicar el candidato que se ha de presentar a recibir los votos de esa clase para Diputado por acumulación.

Al final de su etapa La Lanceta sería al mismo tiempo el órgano oficial del Círculo Odontológico de Cataluña figurando practicantes y odontólogos entre sus redactores, y acabaría desapareciendo en el año 1888.

\section{El Practicante (1884) [3]}

Comenzó su andadura en Zaragoza el 1 de agosto de 1884 y su Director fue el médico don José Ordaz Rubio. Se publicaba tres veces al mes, los días 1,10 y 20 .

Como hemos podido ver, en diciembre de 1884 surge en Zaragoza la idea de crear la Asociación General de Practicantes de España y sería este periódico, El Practicante el medio de propaganda que utilizaría la Comisión Gestora de dicha Asociación para difundir sus ideales de unión de toda la clase de practicantes acudiendo don Laureano García Molino en representación del boletín al Congreso de Barcelona de 1885 .

El Practicante dejó de publicarse a finales de julio de 1887.

\section{La Voz de los Practicantes (1884)}

Contrariamente a lo que dijimos con la publicación de un artículo sobre esta temática de la prensa profesional de los ministrantes y practicantes en España en el siglo XIX, La Voz de los
Practicantes no hizo su aparición en 1865 como algunos autores señalan (Martínez, 1911), sino que lo hizo en enero de 1884 en la localidad castellonense de Morella y no en la tarraconense de Mora de Ebro. A tenor de estos hechos ponemos en duda la existencia de otro periódico de nombre similar, La Voz del Practicante, del que también dimos cuenta erróneamente en el citado artículo.

Sobre La Voz de los Practicantes no podemos precisar más datos salvo la corrección que al respecto de él hemos hecho.

\section{El Defensor del Practicante (1885)}

El primer número de este periódico madrileño vio la luz el 8 de enero de 1885 (Blasco, 1993) y fue dirigida por el practicante don Miguel G. Ramos. Incluía una sección dirigida por el médico don José Martínez Sánchez bajo el rótulo de Dentística (Sanz, 1999) y se publicaba dos veces al mes en cuaderno de 8 ó 16 páginas al módico precio de 5 pesetas anuales.

De lo poco que hemos podido rescatar de este boletín, sabemos que mantuvo un enfrentamiento dialéctico con su colega El Practicante de Zaragoza y que fue crítico con la Asociación General de Practicantes de España porque esta tuvo su principio y desarrollo en Zaragoza y no en la Corte (Herrera, 1995a). En este sentido, Miguel Ramos Director de El Defensor actúo como uno de los Vicepresidentes del Congreso de practicantes de Barcelona en 1885 y el día 9 de abril en la tercera de las sesiones presentó su proposición cuyo primer punto giraba alrededor de la creación de un Comité Central con residencia en Madrid que se ocuparía de la asociación de todos los practicantes de España. Esta proposición fue aprobada por unanimidad y meses después el día 1 de junio de 1885 se redactaba el proyecto de Estatutos de la Liga de Practicantes de España cuya Junta directiva residiría en Madrid con el nombre de Comité Central y conforme a lo aprobado en el Congreso de abril de 1885.

El Defensor del Practicante desapareció del mundo de la prensa sanitaria a finales de 1886 .

El Eco del Practicante (1888)

Los datos obtenidos indican que se publicaba en La Coruña y que su Director y propietario era el practicante municipal de aquella localidad don 
Diego Pazo Cando, antiguo corresponsal del El Practicante zaragozano, aunque hay referencias de que en 1889 su Director era don José Ordaz Rubio, quien anteriormente lo había sido precisamente de este periódico aragonés, y que una vez desaparecido, sería El Eco del Practicante el Boletín Oficial de la Asociación General de Practicantes de España y del que no podemos precisar si tuvo una tirada amplia.

\section{El Fígaro Moderno (1897) [4]}

Empezó a publicarse en Madrid el 21 de julio de 1897 y tenía carácter semanal.

Su propietario y Director fue el periodista don Santiago Puig de Guera y según se puede leer en el encabezado este periódico era el Órgano de la Peluquería, Cirugía Menor, Artes e Industrias similares.

Los practicantes españoles de finales de siglo concentraban sus demandas en aspectos fundamentales como la persecución del intrusismo y la ampliación de sus estudios que en definitiva suponían el merecido reconocimiento profesional.

En junio de 1891 aparece el Reglamento para el Servicio Benéfico Sanitario de los Pueblos que en su artículo $8^{\circ}$ decía que los Ayuntamientos debían sostener practicantes y ministrantes que desempeñasen el servicio municipal de Cirugía Menor. Sin embargo, la realidad era bien distinta, pues la mayor parte de los Ayuntamientos prescindían de los servicios sanitarios de estos profesionales.

Imaginamos que por esta y otras razones surgiría nuevamente en Madrid una Junta organizadora de Practicantes tras una reunión celebrada el día 7 de enero de 1898 y en la que se redactaría un escrito con las proposiciones presentadas por la comisión y que en su base tercera referente a la ampliación de la carrera de practicante solicitaba un examen de ingreso y una duración de los estudios de tres años.

Justo un año más tarde, el 20 de enero de 1899 se volvían a reunir a los practicantes madrileños con el fin de establecer una Junta para la defensa de los practicantes que acabaría fusionándose con la Junta gestora organizadora, adoptando por unanimidad el nombre de Junta organizadora y de defensa de los Practicantes españoles siendo don Salvador Costa Martínez el Presidente de esta
Junta Central de Practicantes Españoles y El Fígaro Moderno su órgano oficial que pudo cesar su publicación al acabar el año 1899.

\section{El Practicante Español (1899) [5]}

Este periódico vio la luz por vez primera el 11 de mayo de 1899 en el municipio soriano de Arévalo de la Sierra. Su Fundador fue el practicante don Federico Oñate López que además sería Director junto al también practicante don Pedro Díaz Domínguez.

El Practicante Español, órgano defensor de la clase de practicantes, irrumpió con fuerza en el mundo de la prensa sanitaria. Por aquel entonces se publicaba en Madrid El Fígaro Moderno al que la dirección y redacción de El Practicante Español miraban con cierto recelo pues no consideraban conveniente que un periódico que era la voz del gremio de los barberos y peluqueros se proclamara a la vez órgano oficial de la clase de practicantes queriendo hacer patente la separación entre estos oficios, tanto es así, que en agosto de 1899 los señores Oñate y Díaz Domínguez enviaron a la Dirección de El Fígaro un documento con las condiciones para la fusión de ambos periódicos en uno sólo, de tal forma que el periódico resultante adoptase el nombre de uno de ellos, El Fígaro Moderno o El Practicante Español. Esta proposición no tuvo aceptación por parte del señor Puig manteniendo desde entonces ambos boletines un enfrentamiento que supuso el inicio por parte de El Practicante Español de una campaña por todas las provincias españolas para lograr la unión de toda la clase, actuando de esta forma frente a lo que ellos consideraban la incapacidad de la Junta Central de Madrid para organizar y defender a la clase de practicantes.

La publicación de El Practicante Español se trasladó a Madrid donde la Asamblea de Practicantes de España tenía su domicilio y de la que Federico Oñate en 1902 era su Presidente. Las rencillas del pasado mantenidas incluso con algunos practicantes de Madrid como el ilustre Salvador Costa le pasaron factura a este boletín. En mayo de 1903 con motivo de la celebración de la I Asamblea de Practicantes de España convocada por el Colegio Provincial de Practicantes de Madrid -que cambió su denominación por la de 
Asociación General de Practicantes de España- se acordó desautorizar a El Practicante Español como el órgano de la clase de practicantes ostentando este privilegio el madrileño El Practicante Moderno, órgano de esta Asociación General de Practicantes de España y que apareció por primera vez el 1 de octubre de 1903. Este hecho no mermaría en la publicación de El Practicante Español que se mantendría algunos años más hasta desaparecer finalmente en 1909.

\section{CONCLUSIONES}

Los ministrantes y practicantes dieron origen a estos periódicos para hacer oír su voz acercándonos de primera mano y con un estilo muy directo a todo cuanto les aconteció durante la segunda mitad del siglo XIX. Sus crónicas fidedignas nos permiten recuperar acontecimientos históricos de vital importancia, tales como la aparición de los primeros colegios profesionales y los intentos que se produjeron desde diversos puntos de España como Zaragoza primero, y Madrid después, para la creación de una asociación de practicantes a nivel nacional y conseguir así la unión de toda la clase que estaba sumergida en el pozo de su propia indiferencia y en el abandono por parte de los poderes públicos. El pugilato que mantendrán ambas capitales, Zaragoza y Madrid por imponer su propio formato de Asociación Nacional de Practicantes les llevará a una constante lucha y enfrentamiento que se trasladará a los periódicos órganos de expresión de estas asociaciones tal y como narran las crónicas que en ellos podemos leer y cuyas disputas alcanzarán incluso a la primera reunión a nivel nacional que hubo de practicantes como fue el congreso de Barcelona de 1885.

De forma más o menos precisa con este trabajo hemos intentado esclarecer los orígenes de la prensa profesional de los ministrantes y practicantes en España en el siglo XIX encontrando signos de la existencia de al menos de 12 periódicos que fueron publicados entre 1864 y 1899 y que de esta manera rescatamos, aunque la mayoría de ellos no se han conservado a día de hoy en bibliotecas públicas españolas, pudiendo acceder tan sólo a una parte mínima del resto de obras con la excepción hecha sobre La Voz de los Ministrantes que se encuentra íntegro prácticamente.
Por lo tanto, concluimos apostando por la localización de las series completas de estos periódicos, así como de otros que aquí no hemos mencionado por desconocimiento de su existencia, y que permitirán completar aquellos años en los que existe un vacío de información y dar así respuesta a ciertos interrogantes que existen sobre el pasado de nuestra profesión.

\section{BIBLIOGRAFÍA}

- Albarracín Teulón, A. (1973): La Titulación Médica en España durante el Siglo XIX. Separata de los Cuadernos de Historia de la Medicina Española XII.

- Amezcua, M.; Germán, C.; Heierle, C.; Del Pozo M. C. (1994): Sanidad y colectividad sanitaria en Almería. El Colegio de Practicantes 1885-1945. Ilustre Colegio Oficial de Enfermería de Almería, Granada.

- Asamblea de Practicantes de España (1902): A S. M. el Rey D. Alfonso XIII Con motivo de su Jura y Proclamación. 17 de Mayo de 1902. Tip. de Luis Montero, Madrid.

- Blasco Ordóñez, C. (1993): La incorporación de practicantes y matronas al sistema sanitario español (1901-1950). Normativas y funciones. Index de Enfermería 4-5, 10.

- Calbet Camarasa, J. M. (1967): Prensa médica en Cataluña (hasta 1900). Tesis doctoral (inédita). Facultad de Medicina de la Universidad de Barcelona. Ejemplar mecanografiado.

- Carbó Lomba, J. (2006): Historia del Practicante en Medicina y Cirugía. Copicentro, Santander.

- Chaves Rey, M. (1995): Historia y bibliografía de la prensa sevillana. Ayuntamiento de Sevilla. Servicio de Publicaciones, Sevilla.

- Colegio Oficial de Diplomados en Enfermería de Madrid (2007): Breve Historia de la Enfermería. Orígenes del Colegio de Madrid. Tribuna Sanitaria 207, 20.

- De Haro Guijarro, J. A. (1903): Memoria de la Asamblea de Practicantes de España Verificada en el Colegio de Médicos de esta Corte en los días 11, 12, 13 y 14 de Mayo de 1903. A. Alonso. Impresor, Madrid.

- De Larra y Cerezo, A. (1905): Historia resumida del periodismo médico en España. La Medicina Militar Española. Imprenta de Ricardo Rojas, Madrid.

- Expósito González, R. (2009): Apuntes históricos sobre el origen del Colegio de Enfermería de Ciudad Real. El Colegio Provincial de Practicantes. Enfermería de Ciudad Real. Revista del Ilustre Colegio de Enfermería de Ciudad Real 52, 27-32.

- Expósito González, R. (2009): La prensa profesional de los ministrantes y practicantes en España en el siglo XIX. Enfermería de Ciudad Real. Revista del Ilustre Colegio de Enfermería de Ciudad Real 54, 30-33.

- Gallardo Moraleda, C.; Gil-Martín Yuste, A.; Jaldón García, E. (1992): Crónica para la historia de la prensa profesional de Enfermería en España (1900-1929). Hygia 21, 30-34.

- Gallardo Moraleda, C.; Gil-Martín Yuste, A.; Jaldón García, E. (1992): Historia de la prensa de Enfermería en Sevilla. Hygia 22, 19-23.

- García Martínez, A. C.; García Martínez, M. J.; Valle Racero, J. I. (1994): Fechas claves de la Enfermería. Híades. Revista de Historia de la Enfermería 1, 66. 
- González Iglesias, J. (1994): Historia de la Odontoestomatología Española. Ediciones Avances MédicoDentales, S. L, Madrid.

- Herrera Rodríguez, F. (1995a): Un periódico aragonés: El Practicante (1885). Híades. Revista de Historia de la Enfermería 2, 153-167.

- Herrera Rodríguez, F. (1995b): Una revista profesional: El Practicante Gaditano (1916-1939). En Libro de Actas de la I Jornada Nacional de Investigación en Historia de la Enfermería Española (Hernández, F. ed.), Universidad Complutense de Madrid. Madrid pp. 57-68.

- Herrera Rodríguez, F.; Lasarte Calderay, J. E. (1996): La prensa andaluza de los practicantes y matronas (1916-1939). En Libro de Ponencias y Comunicaciones del I Congreso Nacional de Historia de la Enfermería (Hernández, F. ed.), Fundación Uriach 1838. Barcelona pp. 169-174.

- Lasarte Calderay, J. E. (1995): La prensa de las profesiones auxiliares sanitarias en Andalucía. Estudio socio-profesional (1916-1939). Tesis doctoral. Facultad de Medicina de la Universidad de Cádiz. Microfichas.

- López Piñero, J. M.; Terrada, M. L. (1990): Bibliographia médica hispánica, 1475-1950. Volumen VIII: Revistas, 17361950. Instituto de Estudios Documentales e Históricos sobre la Ciencia. Universidad de Valencia-CSIC, Valencia.

- Martínez Sánchez, J. (1887): Arte del Dentista. José Serra, Editor. Imprenta de Juan Tarral y Compañía, Barcelona.

- Martínez Sánchez, J. (1911): Bibliografía de la Odontología Española. Índice para formar un catálogo razonado, de las obras impresas en castellano que tratan sobre el Arte del Dentista. Imprenta de La Odontología, Madrid.

- Méndez Álvaro, F. (1866): Defensa de la Clase Médica contra las pretensiones de Cirujanos y Practicantes. Establecimiento
Tipográfico de T. Fortanet, Madrid.

- Méndez Álvaro, F. (1978): Historia del periodismo médico y farmacéutico en España. Universidad de Valladolid, Valladolid.

- Ossorio Bernard, M. (1903): Ensayo de un Catálogo de Periodistas Españoles del siglo XIX. Imprenta y Litografía de J. Palacios, Madrid.

- Sanz Serrulla, J. (1999): Historia General de la Odontología Española. Masson, S. A., Barcelona.

- Unión de Cirujanos, Ministrantes y Practicantes de Barcelona (1866): Estatutos. Imprenta de Magriñá y Subirana, Barcelona.

- Ustrell Torrent, J. M. (1997): Història de l'odontologia. Edicions de la Universitat de Barcelona, Barcelona.

\section{FUENTES:}

- "El Imparcial": XXXVII (1903), 12970, p. 4.

- "El Practicante": II (1885), 27, p. 210-212.

- "El Practicante": II (1885), 34, pp. 266-268.

- "El Practicante Español”: I (1899), 1, p. 2.

- "El Siglo Médico": XXXI (1884), 1603, p. 592.

- "El Siglo Médico": XXXI (1884), 1605, p. 623.

- "El Siglo Médico": XXXII (1885), 1637, p. 304.

- "Enciclopedia Médico-Farmacéutica": VIII (1884), 34, p. 532.

- "La Vanguardia": III (1883), 517, p. 7285.

- "La Vanguardia": III (1883), 537, p. 7559.

- "La Vanguardia": V (1885), 15, p. 218.

- "La Vanguardia": XIII (1893), 3754, p. 3.

- "La Vanguardia": XXIII (1903), 8882, p. 3.

- "La Voz de los Ministrantes": I (1864), 10, pp. 73-74.

- "La Voz de los Ministrantes": I (1864), 16, pp. 121 y 127.

- "La Voz de los Ministrantes": I (1864), 21, pp. 167-168.

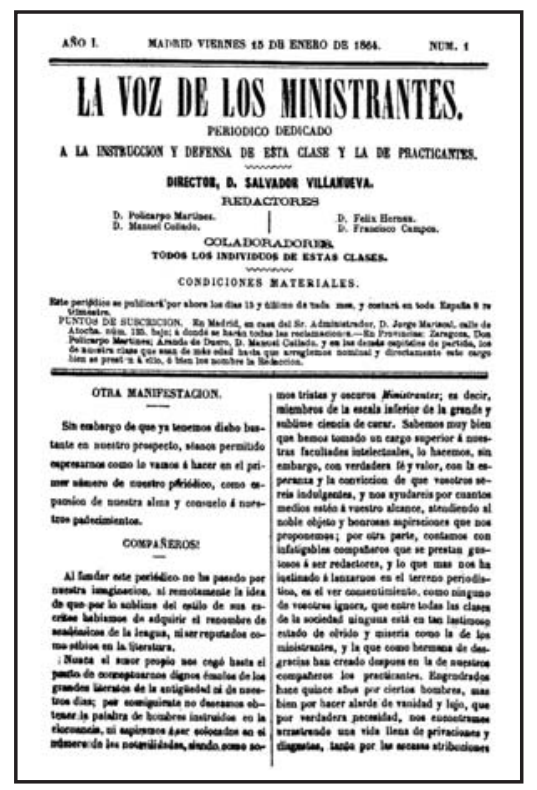

Fig. 1. Primera página del número 1 de La Voz de los Ministrantes (1864).

Fig. 2. Primera página del número 68 de La Lanceta (1887).

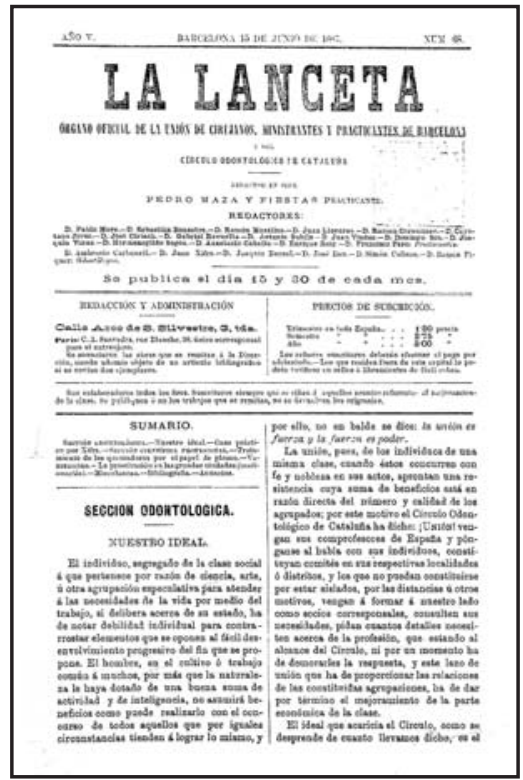


- "La Voz de los Ministrantes": II (1865), 27, p. 23.

- "La Voz de los Ministrantes": II (1865), 30, pp. 43-46.

- "La Voz de los Ministrantes": II (1865), 37, p. 103.

- "La Voz de los Ministrantes": III (1866), 91, p. 246.

- "La Voz de los Ministrantes": IV (1867), 102, p. 52.

- "La Voz de los Ministrantes": IV (1867), 114, p. 152.

\section{NOTAS}

[1] Ejemplares localizados en la Biblioteca de la Facultad de Medicina de la Universidad Complutense de Madrid desde el año 1864 hasta el año 1866 (completos). Gracias a la información por cortesía de Carlos Álvarez Nebreda sabemos que también se conserva el año correspondiente a 1867 en la Hemeroteca Municipal de Madrid. En esta hemeroteca podemos encontrar la colección completa desde el año 1864 hasta el año 1867, con la excepción del número 96.

[2] Martínez Sánchez en 1911 habla de la existencia de dos periódicos que aparecen con el mismo título, uno en 1882 y otro en 1883 siendo sus Directores don Pedro Maza y Fiestas y don Pedro Manaut y Taberner respectivamente. En base a los datos manejados se trata de la misma publicación que no hizo pública su aparición hasta el 15 de noviembre de 1883 y en la que el señor Manaut actuaba como Directorcientífico y el señor Maza como Redactor-jefe en 1887 tal y como hemos señalamos anteriormente. Tan sólo hemos encontrado el número 68 correspondiente al 15 de junio de 1887 en la Hemeroteca del Archivo Histórico de la Ciudad de Barcelona.

[3] En 1995 con el artículo Un periódico aragonés: El Practicante (1885) Francisco Herrera hizo una magnífica revisión de los números localizados correspondientes al año de 1885 en la Biblioteca de la Facultad de Medicina de la Universidad de Zaragoza.

[4] Nosotros hemos localizado en la Hemeroteca Municipal de Valencia los números 27 y 28 correspondientes al año 1898. Gracias a la información por cortesía de Carlos Álvarez Nebreda sabemos que también hay ejemplares en la Hemeroteca Municipal de Madrid correspondientes al año 1899 (números 125-129).

[5] En la Biblioteca Pública del Estado de Soria se encuentran los 23 números publicados en 1899 .
Fig. 3. Primera página del número 47 de $\mathrm{El}$ Practicante (1885).

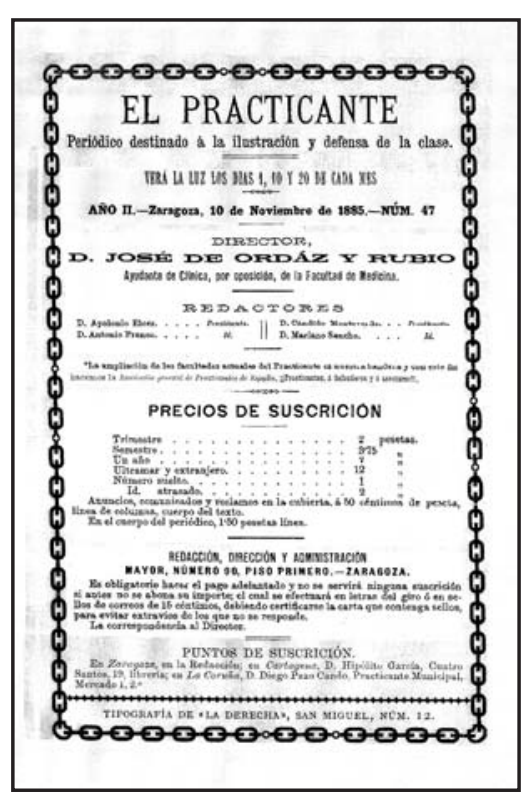

Fig. 4. Primera página del número 28 de El Fígaro Moderno (1898).

Fig. 5. Primera página del número 1 de El Practicante Español (1899).

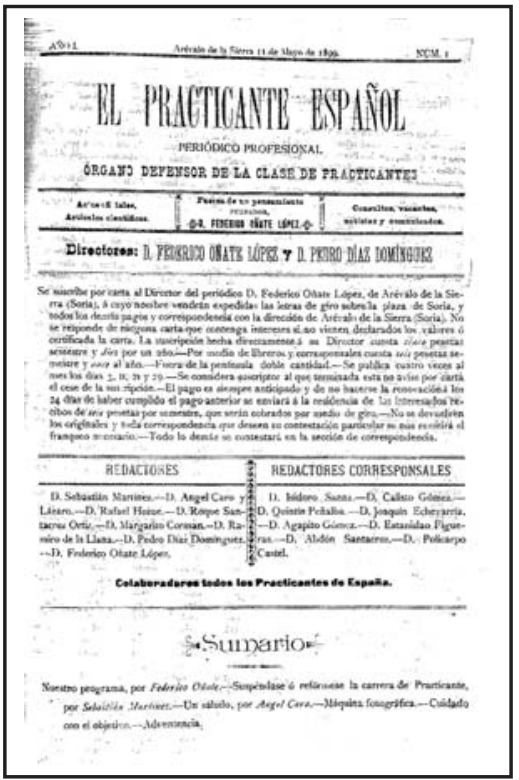

